\title{
Income Inequality in the South-South Integration
}

\author{
Yvonne Sperlich \\ Université de Genève, Geneve, Switzerland \\ Stefan Sperlich \\ Université de Genève, Geneve, Switzerland
}

\begin{abstract}
Some of the findings from new trade and economic geography theory are quite critical concerning the South-South agreements. This study contributes to the discussion by means of different empirical analyses of a representative set of South-South integrations. The income developments of its member states are studied with a special focus on income dispersion between and within member states. The results show that income dispersion has slightly decreased, within and between member states. The findings are placed in relation to growth models and beta convergence as other studies have found ambivalent results for growth and convergence in South-South integration areas.
\end{abstract}

JEL Classifications: F15, F43, O43, O11, E13

Key Words: South-South Integration, Regional Integration, Income Inequality, Sigma Convergence, Development Economics

\footnotetext{
* Corresponding Author: Yvonne Sperlich; Geneva School of Economics and Management, Université de Genève, Bd du Pont d'Arve 40, Genève, Switzerland; Tel: +41 2237998236, Fax: +41 223798299, E-mail: yvonne.sperlich@ unige.ch.

Co-Author: Stefan Sperlich; Geneva School of Economics and Management, Université de Genève, Bd du Pont d'Arve 40, Genève, Switzerland; Tel: +41 223798223, Fax: +41 223798299, E-mail: stefan.sperlich@unige.ch.

Acknowledgement: The authors appreciate a lot helpful discussions with Marcelo Olarreaga (Universität Göttingen), Ricardo Mora (Univ. Carlos III de Madrid), Walter Zucchini (Universität Göttingen), Inmaculada Martinez-Zarzoso (Universitat Jaume I). The first author acknowledges financial supported from the Swiss National Science Foundation MHV-PMPDP1-151444; the second author from project 100018-140295.
} 


\section{Introduction}

It is still disputed to what extent South-South agreements, that is, among developing countries, is boon or bane for growth and development of their member states. Main criticisms are that they would lead to increasing income disparity and trade diversion at the expense of the poorest regions. One clear distinction required here is the inequality between countries and the inequality within countries. This is essential to counter the obvious argument that one might have sigma-convergence of GDP per capita but an increasing inequality within each member state or, last but not least, a divergence of the income distributions. ${ }^{1}$ The paper therefore provides both empirical facts about the income development including sigma convergence, and about the development of income dispersion inside the member states of Regional Integration Areas (RIAs). We consider the per capita income paths and the income dispersion of the member states. More specifically, we have analyzed to this respect a sample of RIAs in South Asia, South America, and West and Central Africa over the last four decades. We selected them mainly along the following criteria: RIAs founded only by developing (low and lower income) countries, and under the GATT/WTO enabling clause. For Latin America the ANDEAN ${ }^{2}$ Community and MERCOSUR ${ }^{3}$ are the cases; for South Asia the $\mathrm{ASEAN}^{4}$; and for Africa the CEMAC ${ }^{5} \mathrm{WAEMU}^{6}$, and ECOWAS ${ }^{7}$.

Growth and income development was typically measured by GDP per capita. Nowadays, however, an increasing importance is also given to additional information on the income distribution, e.g. by looking at some quantiles, dispersion, or inequality measures. Often used measures to analyze income inequality are the sigma dispersion, the Theil populations-weighted index, and the Gini index (Rey and Janikas 2005). The Gini index is inadequate for country sets but used to measure inequality inside countries,

\footnotetext{
'This is often the main argument of opponents of globalization and (trade) openness.

${ }^{2}$ Its members are Bolivia, Colombia, Ecuador, Peru, and until 2006 also Venezuela.

${ }^{3}$ Members are Argentina, Brazil, Uruguay and Paraguay, and Venezuela since 2012. Associated members are Chile (since 1996), Bolivia (1997), Peru (2003), Ecuador and Colombia (both 2004).

${ }^{4}$ Indonesia, Malaysia, Thailand, Singapore, Philippines, Brunei (since 1984), Vietnam (1995), Burma-Myanmar (1997), Laos (1997), Cambodia (1999), and Papua New Guinea (associated since 1984).

5 CEMAC (Economic and Monetary Community of Central Africa) members are Cameroon, Central African Republic, Chad, Rep. Congo, Equatorial Guinea, and Gabon.

${ }^{6}$ West African Economic and Monetary Union members are Benin, Burkina Faso, Cote d'Ivoire, Guinea Bissau, Mali, Niger, Senegal, and Togo.

${ }^{7}$ Its members are Benin, Burkina Faso, Cape Verde, Cote d'Ivoire, Gambia, Ghana, Guinea Bissau, Guinea, Liberia, Mali, Mauritania (until 2001), Niger, Nigeria, Senegal, Sierra Leone and Togo.
} 
and the Theil index is mainly interesting for decomposing the cross-national disparity of inequality within and between groups. The discussion of pros and cons of South-South RIAs mainly focuses on growth, or growth per capita, and the sigma or beta convergence for measuring divergence or convergence dynamics between countries.

Based on the Solow growth model, Sperlich and Sperlich (2011) found conditional and unconditional $\beta$-convergence, and enhanced growth inside most of the considered RIAs, namely MERCOSUR, ASEAN, WAEMU, CEMAC, and ECOWAS. This was in accordance with te Velde (2011) or Michelis and Naeime (2004), Fugazza and RobertNicoud (2006) or Martincus and Siedschlag (2010). A different but politically important question is the $\sigma$-convergence and inequality in South-South agreement areas (BenDavid 1993). The same holds true for inequality inside the countries (Panizza 2002). Barro and Sala-i-Martin (1992) highlighted why it is important to consider not only the $\beta$-but also the $\sigma$-convergence of income development. While $\beta$-convergence represents the long-term mobility of income (Sala-i-Martin 1996), the $\sigma$-convergence shows the disparity of log per capita income over time among members. Politically, the latter is often emphasized than the first, and also the inequality inside countries has become an increasing issue in the political discussion. This is the reason why we will also compare the different measures for our South-South RIAs. Apart from that, even the integration theory seems not to be based on a uniform model theory but rather on several, partly competing, theories. For example, the trade theories provide other pros and cons of South-South RIAs like the growth theories. We start with a summary of the most typical pro and contra arguments found in the existing literature.

The trade theories assume that RIAs lead to trade creation and diversion. In contrast, the growth literature criticizes that South-South agreements generate socalled convergence clubs at the low income level (Quah 1996). This club convergence hypothesis competes with the absolute or conditional convergence hypothesis (Galor 1996). A main factor causing convergence in RIAs is the knowledge and technology transfer, a stress of competition, and efficient compensation mechanisms. But along with Quah (1996), integration areas need the participation of strong economic leaders and openness to avoid the poverty trap. Arguments supporting the hypothesis of increasing inequality in South-South agreement areas are, for example, the non-complementary production and trade structures of the members, the agglomeration of manufacturing industries in relatively richer countries, and the stronger trade diversion at the cost of the poorest members.

The endogenous growth models implicate divergence for RIAs after the foundation, 
because of negative effects though market liberalizations for the short- and mediumterm (Krugman 1991). Baldwin, Martin, and Ottaviano (2001) pronounce strongly in favor of free-trade to reach perfect international or regional transmission of learning externalities, recommending open regionalism. Goodfriend and McDermott (1998) argue that the key factor of convergence processes is the openness to foreign ideas and technologies; a closed regionalism between developing countries must cause divergence due to the lack of new technology and innovating capacity.

In sum, the trade theory, as well as the new economic geography, advises against regional integration among low income countries. Also, the empirical studies typically show ambiguous pictures but with findings more in favor of RIAs. One of our main points is that almost all theoretical studies abstract from other long-term targets, for example, mechanisms such as political stabilization of regions. In fact, it is well-known that for energy and environmental policy, epidemics control, and infrastructural policy, at least intra-regional coordination is needed (Hammouda, Karingi, Njuguna, and Jallab 2009).

This paper contributes by providing a unique empirical analysis of income development concerning South-South agreements. We use long-term data sets to consider entries and exits from the beginning of the 1970s until 2008. Implications of beta and sigma convergence are discussed. After a brief review of each individual GDP path, we filter out the business cycles and consider different subsamples to correct for late entries of especially poor, or the impact of suddenly ${ }^{8}$ rich countries. The real GDP per capita in international PPP is taken from the World Development Indicator database. The rest of the paper is organized as following: In the next section, we introduce all RIAs reviewing the income paths of each member state. Section III studies the development of inequality within the respective countries, comparing the Gini indices between countries from the 80s and in 2008. In Section IV, we look at the sigma convergence results and compare them with preceding findings on growth and convergence, revisiting the relation between $\beta$ - and $\sigma$-convergence in Section V. Finally, Section VI concludes.

${ }^{8}$ This used to happen when oil resources were discovered. 


\section{A Sample of South-South Integration}

\section{Figure 1. Members and associates of MERCOSUR and ANDEAN ${ }^{9}$}

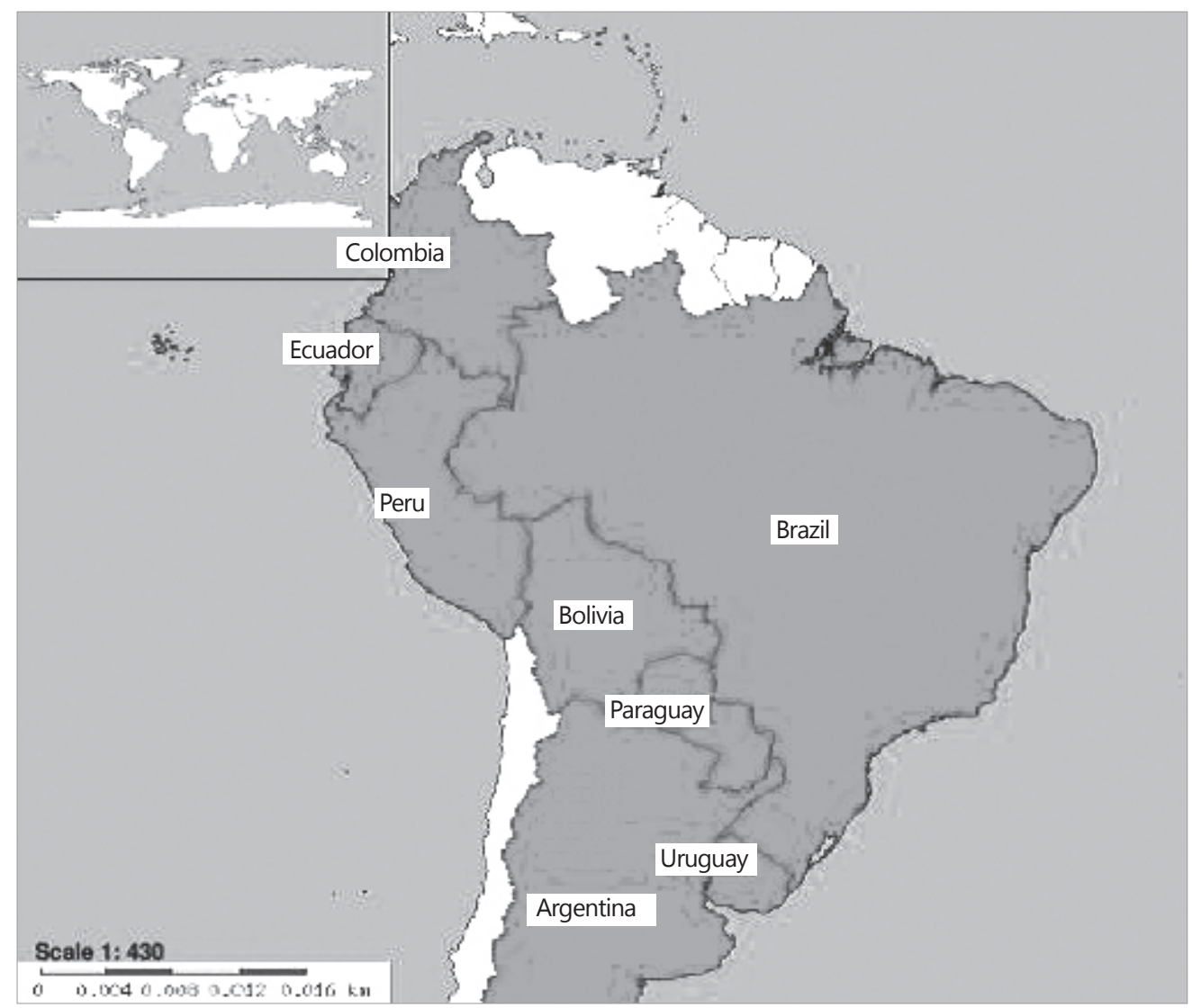

We start with a look at MERCOSUR and ANDEAN in Latin America. The official targets of MERCOSUR are the creation of an internal market with a free flow of goods, services, and production factors between member states. Moreover, the members have committed themselves to coordinate their economic, fiscal, and monetary policy. While the MERCOSUR was founded in 1991, the associated members have formed the ANDEAN in 1969. The goal of the latter was catching-up economically to the richer Latin America countries. Due to data limitations, we consider the period 1975 2008. Note that the integration process of the MERCOSUR founders already began in 1986 via

\footnotetext{
${ }^{9}$ Source of all maps: http://www.cris.unu.edu/map/map.phtml; Note: Chile has a special status as associated country in both RIAs
} 
bilateral agreements.

Figure 2 shows the income developments for the countries belonging today to the MERCOSUR (including the associated members) and the ANDEAN. After important severance charges caused by the introduction of the Plano Austral 1985 1986 in Argentina and the Plano Cruzado 1985 1986 in Brazil, respectively, the economies recovered only momentarily, and then both countries reached an inflation rate of more than $1000 \%$ before they used Brady Bonds in 1989 to securitize credits yielding a successful financial restructuring in cooperation with the International Monetary Fund.

Figure 2. Log per capita income in MERCOSUR and ANDEAN

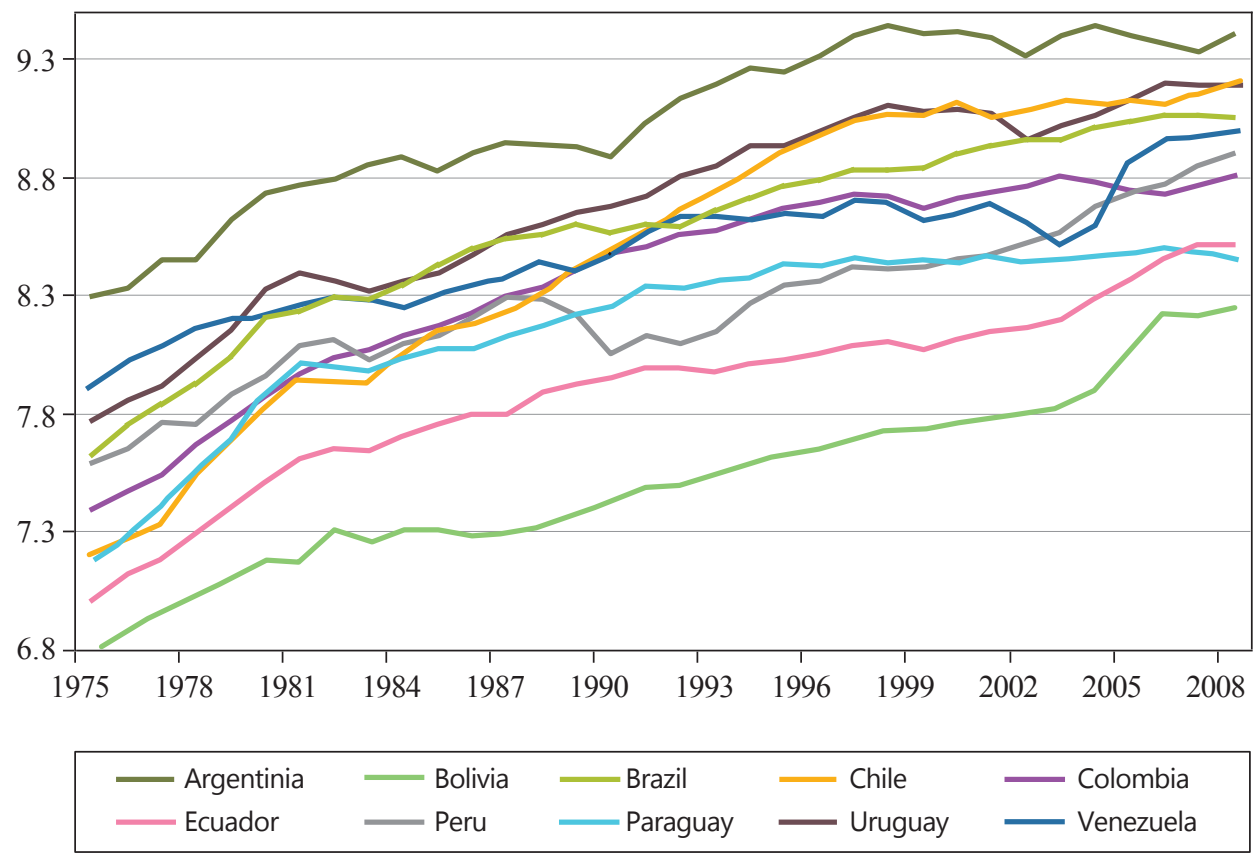

Since then, we observe a quite steady economic growth until the recession in 1998 and the impact of the financial crisis in 2001, especially for Argentina. Uruguay participated in the Brady Bonds round and also succeeded in stopping its inflation. Having hardly any FDIs and depending mainly on Argentina and Brazil, its economic growth has basically been moving alongside that of Argentina since 1990. Paraguay was by far the poorest founder of MERCOSUR. It had been a closed, agriculture oriented country until the end of the dictatorship of Stroessner in 1989. Today, agriculture still 
makes almost $30 \%$ of the GDP. It suffers from the typical afflictions like high inflation, and a serious national debt. Since the crisis in 1997, its GDP per capita is stagnating.

If we look at the ANDEAN countries, what stands out the most is the different development level observed in Peru compared to the rest, especially from 1987 to 1995. These are the consequences of a bundle of economic reforms towards liberalization (decentralization, opening for FDIs, and improvement of infrastructure) after a long period of dictatorships during 1968 1980. Ecuador is the second poorest country of Latin America where $60 \%$ of its export is petroleum so we can imagine the impact of the OPEC crises in 1986. At the end of the 1990s, hyperinflation and recession led to a general economic crisis ending basically with the substitution of their own currency by the US dollars in 2000. Columbia performed quite well despite the permanent conflicts with drug syndicates and the FARC. Chile is the second richest country of Latin America but has had a serious problem of inequality (like Brazil, Colombia, and Bolivia) and poverty. Today, it has a mainly market oriented system with a treasury rate below $20 \%$. It is the largest exporter of copper; the crumbling of copper prices around 1998 is evident, cf. Figure 2. For Venezuela, it was the oil price decline that has had disastrous consequences as oil export made about $60 \%$ of the total exports. High national debts, hunger revolts, e.g. in 1989, and the IMF policy during 1994 1998, led finally to Chavez' socialism of the $21^{\text {st }}$ century with several nationalizations. Since 2002, we observe economic stagnation and finally recession. For more details see, among others Bulmer-Thomas (2003) or Thorp (1998).

Figure 3 and 4 shows our second RIA ASEAN (Association of Southeast Asian Nations) which was already founded in 1967, but at that time the cooperation was only security-political oriented. Annual meetings of the ministers for economic affairs have been held since 1975. Only since then has the character of the cooperation become more economically orientated. Therefore, we again start the testing period in 1975 . The cooperation is getting more and more dynamic since the end of the cold war, especially among new member countries. Specifically, in 1992 the ASEAN FTA was signed, and in 1994 the ASEAN Regional Forum founded. Because of absent data, we had to exclude Brunei and Burma (Myanmar), while we could not include Cambodia, Vietnam, and Laos before the 80 s. 


\section{Figure 3. Members and associates of ASEAN}

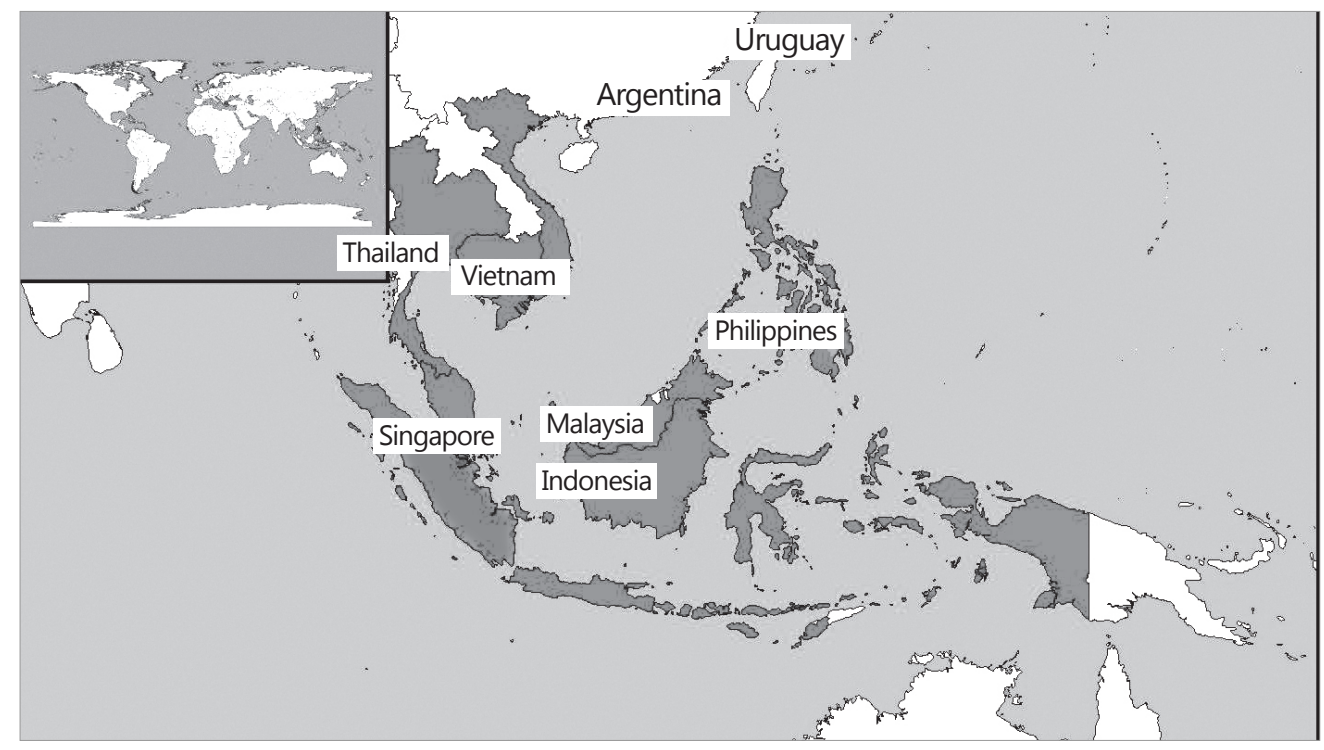

Not surprisingly, among the founders, the city state Singapore has experienced the strongest economic growth. Today, services make about $70 \%$ of its GDP. The main reasons are an extremely deregulated financial hot spot and the harbor being an important trans-shipment center for overseas trade. In contrast, Indonesia has always been one of the poorest founder state although it participated in the general upwards trend until the Asian crisis in 1997. Malaysia and Thailand exhibit rather similar GDP per capita paths except that Malaysia stagnated for three years around 1985 when prices for oil and palm oil dropped. Both have coped with a slow but steady industrialization. The Philippines exhibit a serious inequality between the poor agrarian south and the industrialized north. In its per capita growth path, we see the impact of the economic crisis and riots against the dictator Marcos in the mid 80s, and the eruption of the volcano Pinatubo in 1991. Note that all ASEAN founders are export oriented and therefore also depend on the same global business cycles today. For more details see Hill (1994). 
Figure 4. Log per capita income of the ASEAN members

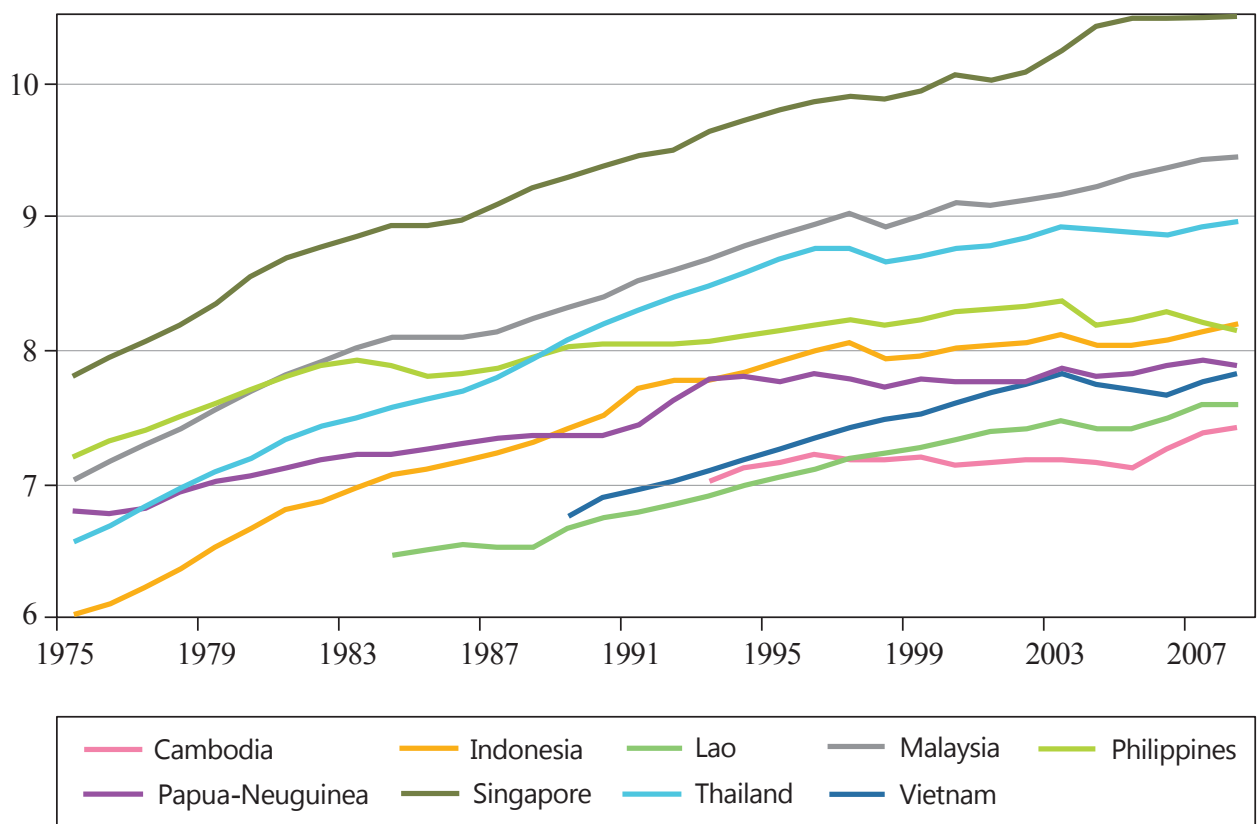

Figure 5 to 8 shows the two African custom and monetary unions, WAEMU and CEMAC which were both founded 1994 . The nominally common currency is the CFAfranc with the central bank BCEAO in Dakar for the WAEMU, and a central bank BEAC in Yaoundé for the CEMAC. The cooperation concentrates on the improvement of infrastructure, an efficient energy policy and some macroeconomic coordination to develop common markets, reduce poverty, and to combat AIDS. Due to the lack of data we had to drop Liberia; Equatorial Guinea, Guinea and Cape Verde are included only from the mid 80s onwards. The income paths are plotted in Figure 6 and 8.

We start by considering the CEMAC (Central African Economic and Monetary Community) member's income paths, see Figure 5 and 6. Most striking is with Equatorial Guinea where since the discovery of large oil reserves in 1991, it exhibited extraordinary growth rates. However, despite a GDP per capita of more than 30,000 US dollars in 2008 (the ninth highest in the world) it has ranked 121 out of 177 countries on the Human Development Index of the UN. Also, Gabon is rich in natural resources of which oil makes about $80 \%$ of its export. Consequently, the economy strongly depends on the international oil market, clearly shown in a decrease of GDP in the mid 80s when the oil price dropped. Cameroon had been in recession from the mid 80s until the mid 
90s due to an overrated currency, political mismanagement and high corruption. In order to solve this, in 1994 it started with devaluation and IMF advised restructuring the economy.

Figure 5. CEMAC members

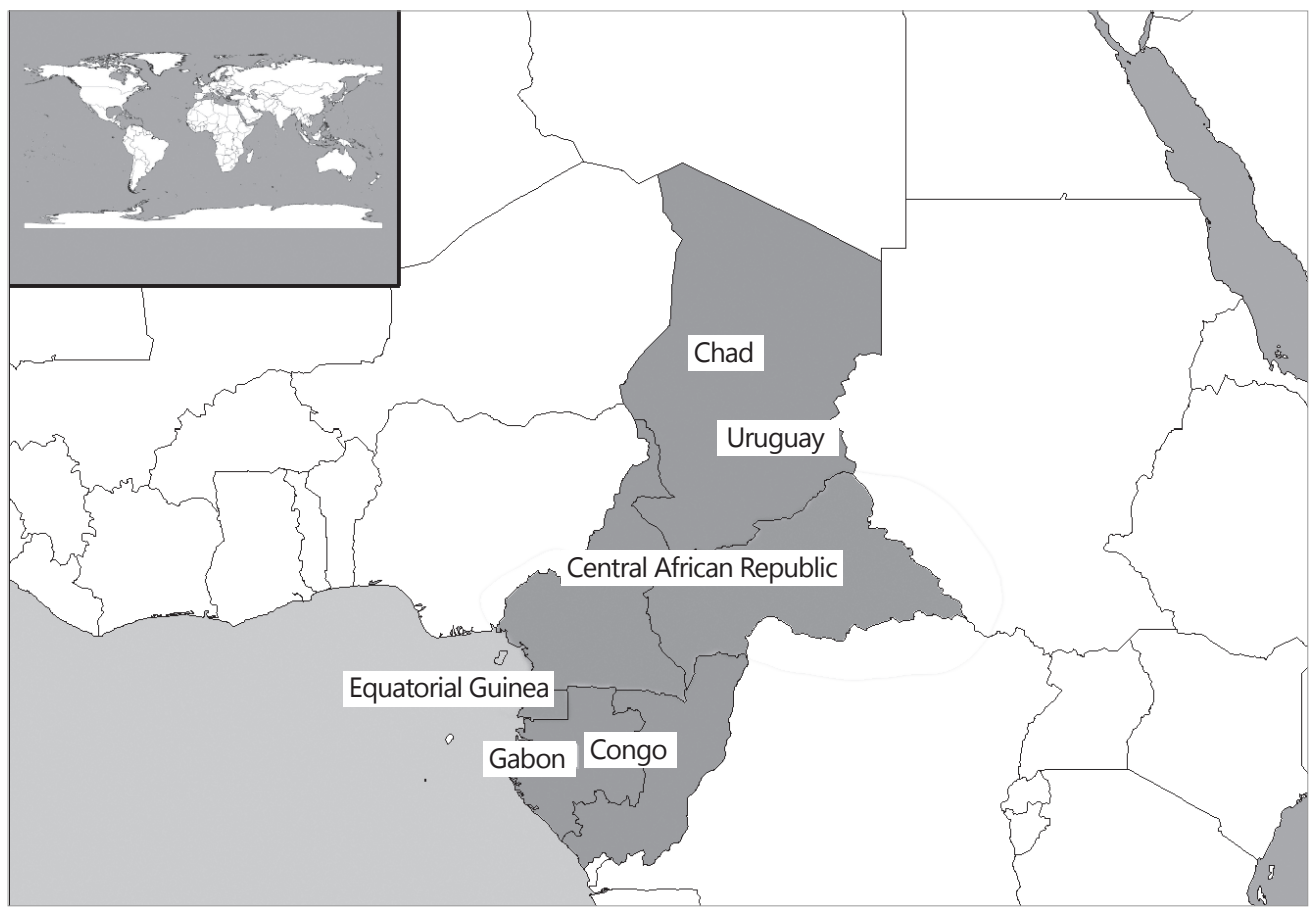


Figure 6. Log per capita income of the Economic and Monetary Community of Central Africa members

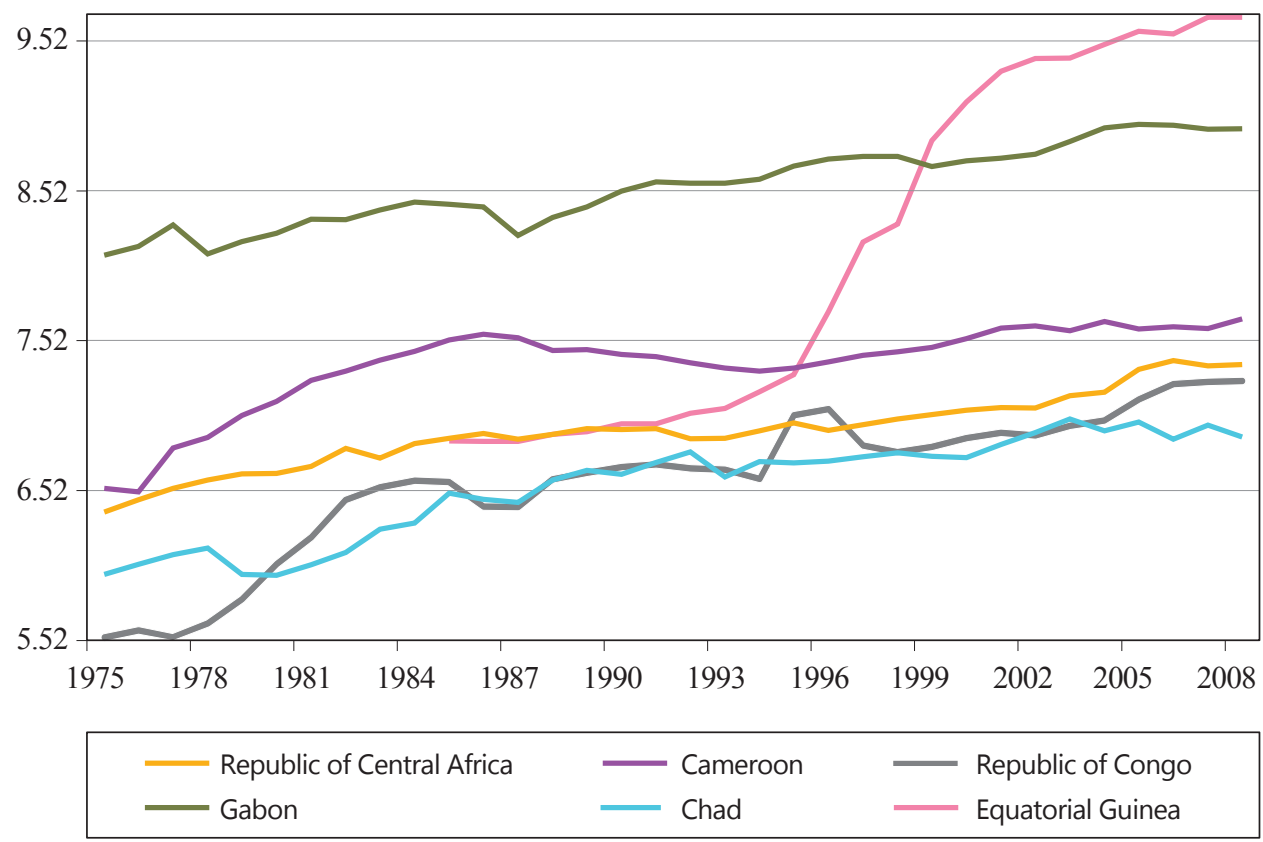

The Republic of Central Africa has been deeply affected by the civil wars in Sudan, experiencing an enormous immigration of refugees. Additionally, their own democratization process was slow until 1995 due to its many military revolts. Similary, Chad has also been suffering different internal political and military conflicts, except in the 90s. At that time, the oil reserves were discovered, but Chad exported almost no oil before 2002. Finally, the Republic of Congo had a socialist economy until 1990 resulting in high unemployment and serious external debts, and from 1997 to 2002, three civil wars took place.

As Figure 7 and 8 show, many countries within the West African Economic and Monetary Union (WAEMU) depend on primary exports. Cote d'Ivoire is the world leader in cacao production and was therefore especially affected by the price decrease for cacao since 1980 followed by economic crises and a civil war in 2002. 


\section{Figure 7. WAEMU members}

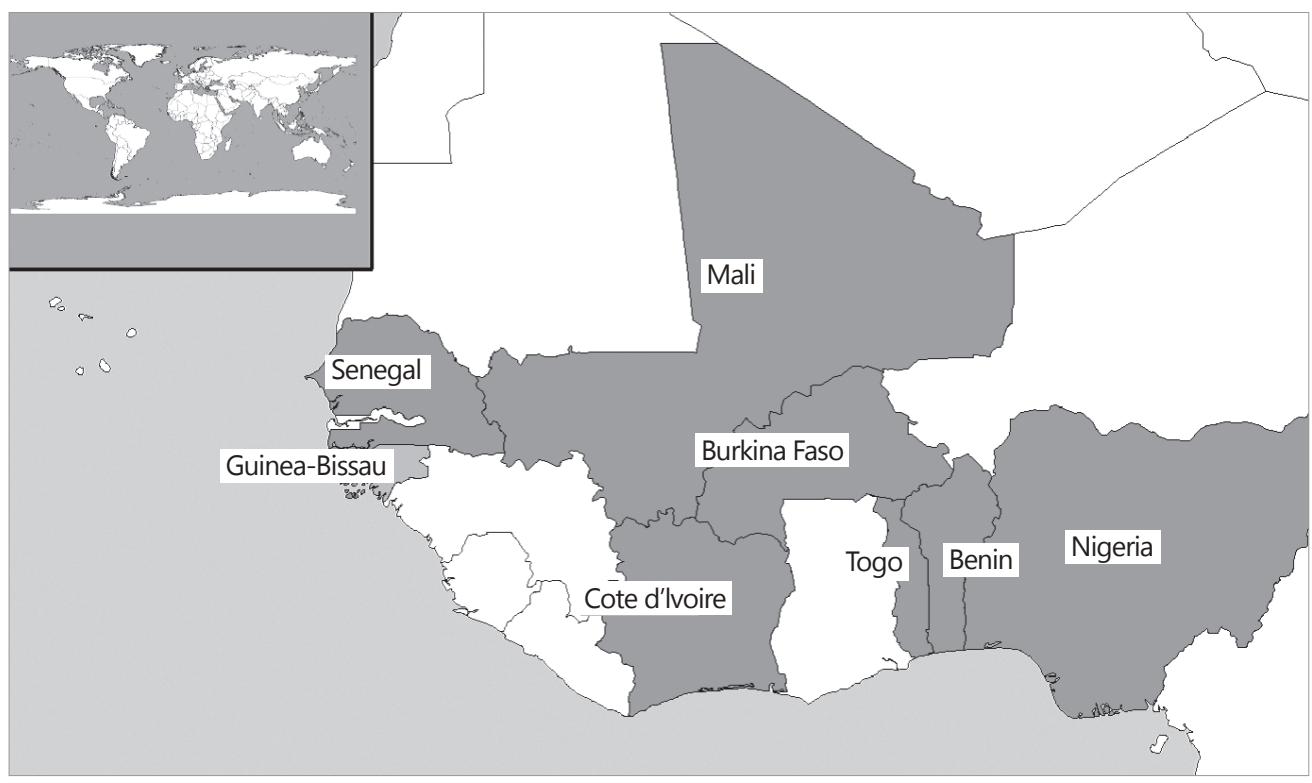

Besides, it is the only oil-exporting country in the WAEMU (Goretti and Weisfeld 2008). Togo's economic situation improved notably after some IMF reforms in 1979. Nevertheless, its economy still depends strongly on its traditional products of cacao, coffee and, also since 1990, cotton. But Togo is also an important re-export port for automobiles. Guinea-Bissau had a steady growth until the beginning of political unrests in 1997. Until the mid 80s, Niger had implemented a policy of development agencies. Several bad harvests and a quite high fertility rate led to subsequent stagnation. In contrast to the other WAEMU members, Senegal has a significant industry for the subsequent processing of primary goods, especially for food and textiles. Therefore, though its main export goods are based on peanuts and cotton, it is less affected by price changes for primary goods on the world market. Actually, in 2000, primary goods constituted only $2 \%$ of Senegal's total export. 
Figure 8. Log per capita income of the WAEMU members

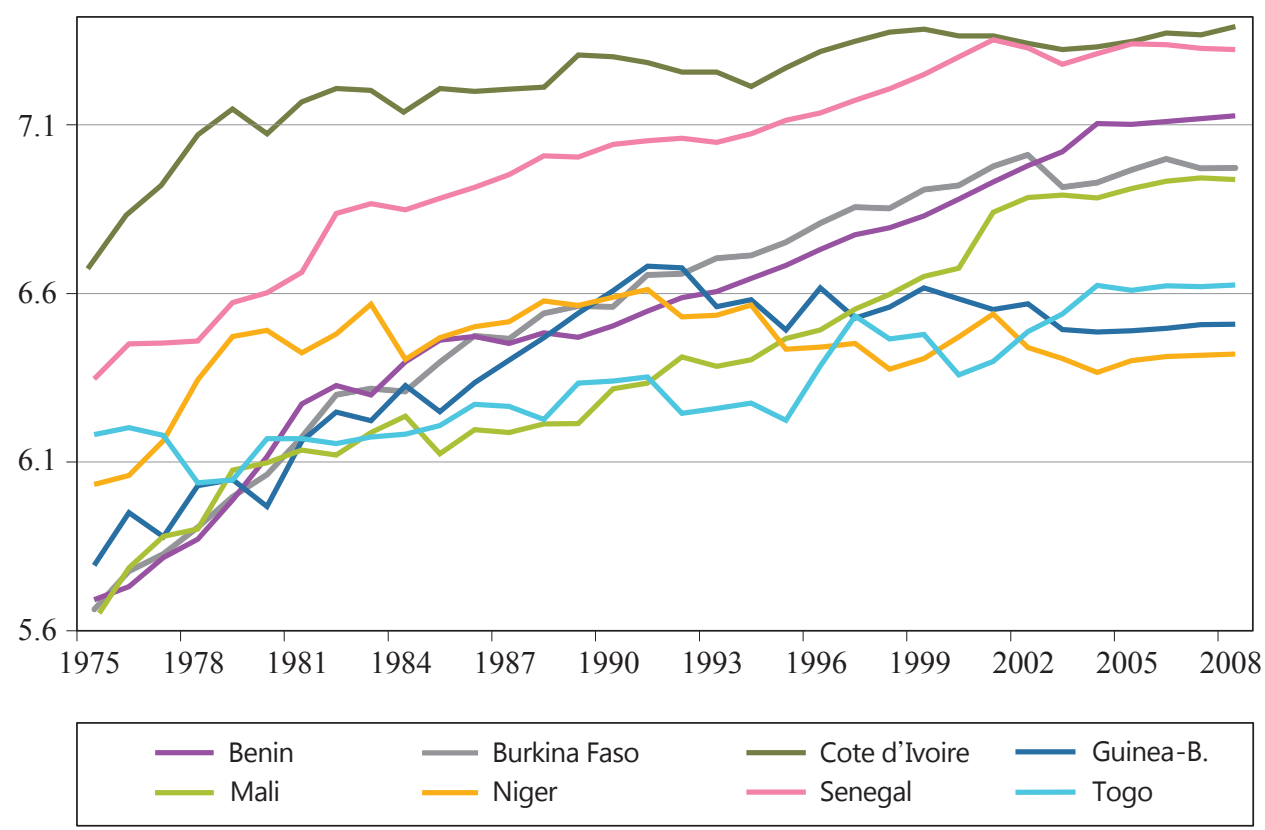

The third selected African RIA is the ECOWAS. It was founded in 1975 through the treaty of Lagos, and has been a free trade area since 1999. An important cooperation field is the sectoral programs which aim at an intra-connection of national electric grids and a regional pipeline for the distribution of natural gas, an improvement of the intraregional infrastructure as well as a security mechanism.

Due to the overlapping memberships of ECOWAS with CEMAC and WAEMV, the developments of some of the ECOWAS members, shown in Figures 9 and 10, have already been discussed. Ghana participated after 1983 in an IMF restructuring program with a devaluation of its currency. Its export is dominated by gold, diamonds, and agricultural goods. The economic growth of Nigeria is based on oil exports but thwarted by mismanagement, corruption and a military regime (1993 1998). Today, it has also a growing telecommunication sector. Guinea implemented some economic reforms in 1985, liberalized its rules for FDIs in 1998, and has several joint ventures, especially in the mining sector. Gambia acts as a re-exporter as it has hardly any natural resources. 


\section{Figure 9. The map of ECOWAS members}

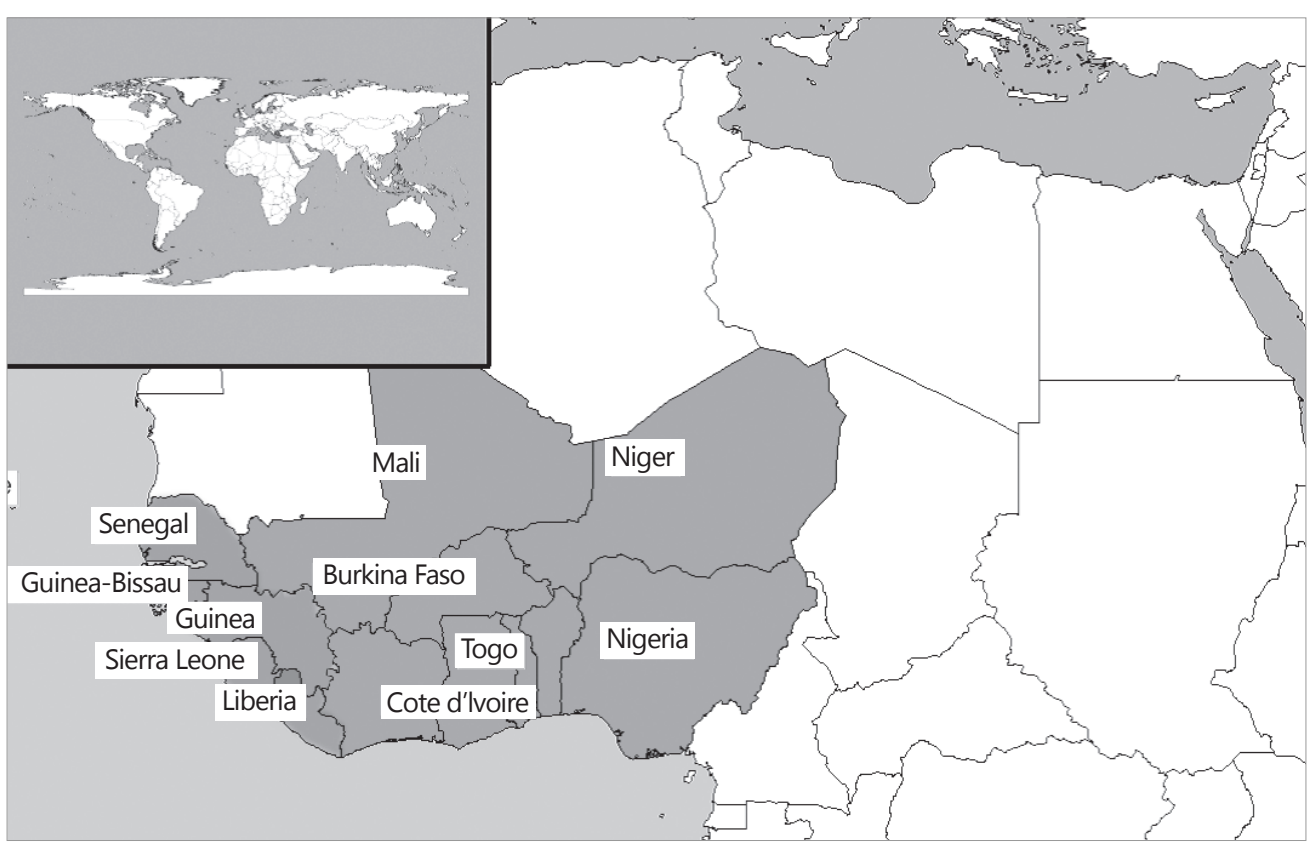


Figure 10. Log per capita income of the ECOWAS members

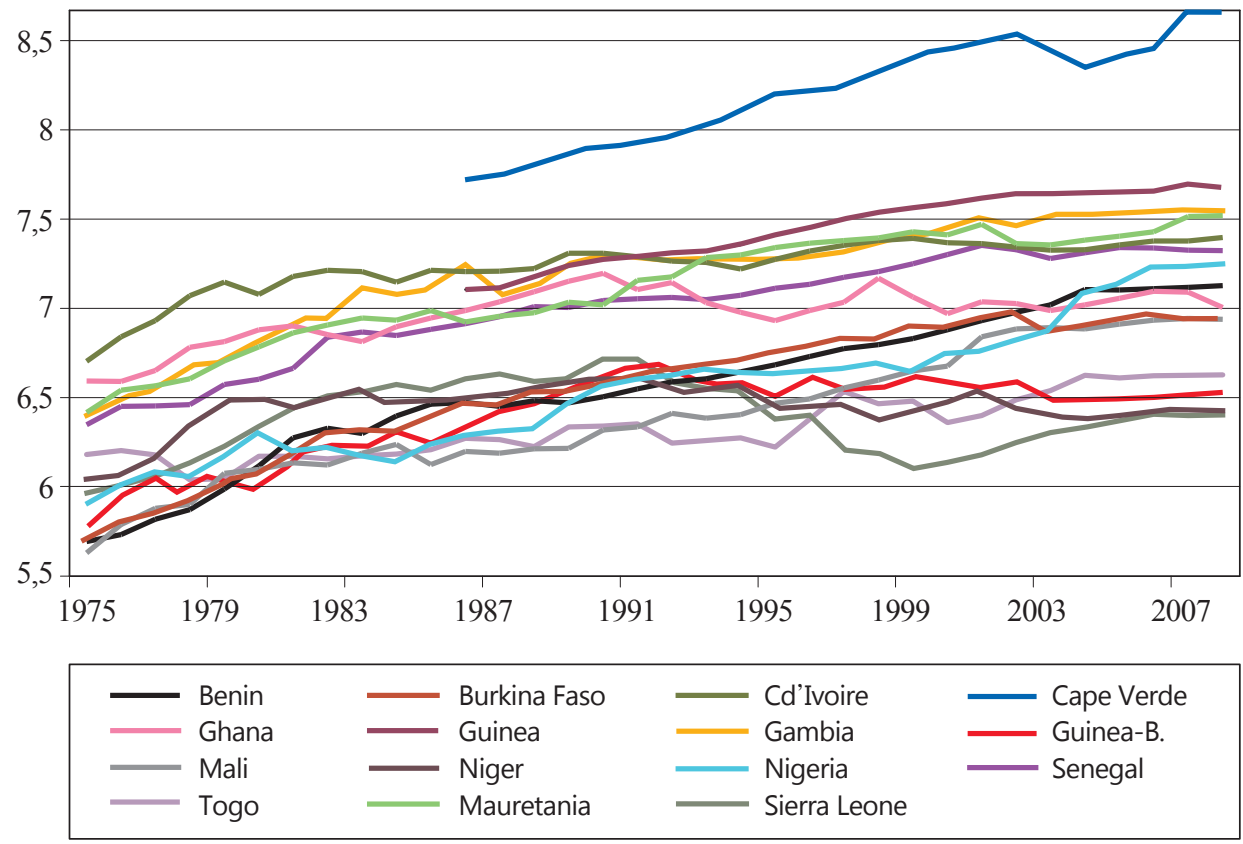

More than $80 \%$ of Sierra Leone's exports are raw minerals. Since 1991, the exploitation of diamonds has decreased due to a civil war, and a main part of its export is illegal diamond smuggling. From its independence in 1975 until 1990, Cape Verde had been a communist system before it changed to a neoliberal service-oriented market economy that mainly relies on tourism and trade. For the African countries, we observe no business cycle synchronicity (Oyebade and Alao 1998).

Time tables provided in the Appendix for the three world regions discussed can summarize some of the above mentioned key dates.

\section{The Development of Income Inequality}

Not only in poverty and development economics is it today broadly accepted that our interest should go beyond the average GDPs when looking at income and growth (Ravallion 2001). The common literature would, as a follow-up of Section II, study 
models of income and growth, and maybe test for beta- and/or sigma-convergence in each RIA. Studies which are rather interested in inequality and/or poverty would look at particular income quantiles or some inequality measures. A simple and easily available indicator of inequality and thus the income distribution is the Gini index. Before we look at the convergence of mean incomes (i.e., the GDP per capita) inside each RIA, we first study the development of this well-known distribution parameter. This will tell us to what extent country specific income dispersions have changed and maybe converged towards a similar, hopefully lower, dispersion/inequality level for all members of the same South-South RIA.

For Latin America, the Gini indices ${ }^{10}$ are summarized in Table 1 for the mid-80s and for around 2008. ${ }^{11}$ First, we see that all Latin American countries have had a relatively high $^{12}$ Gini of more than 40 . We also see that there is no unique development where some countries' inequality went up while it dropped down for others. On average, inequality has rather shrunken than increased over all countries, from a mean of $52.8^{13}$ to 50.1. This average, however, is not weighted by population. For the subset of founder states it has slightly increased. In total, we see here a clear convergence; the dispersion of $6.55^{14}$ in the mid-80s among all considered countries has fallen to 5.28 in 2008. This convergence is even stronger if these calculations were repeated for MERCOSUR and ANDEAN separately. It is notable that the inequality went up only for Argentina and Paraguay after MERCOSUR was founded, where for the latter, this is rather linked to the end of the Stroessner era.

Table 1. Gini indices for Latin America

\begin{tabular}{|c|c|c|c|c|c|c|c|c|c|c|}
\hline & Argentina & Bolivia & Brazil & Chile & Colombia & Ecuador & Paraguay & Peru & Uruguay & Venezuela \\
\hline Mid 80s & 44.5 & 59 & 59 & 57 & 59.1 & 51 & -- & 46 & 43.7 & 55.6 \\
\hline Around 2008 & 45.8 & 56.8 & 53.9 & 52.3 & 57.6 & 49 & 52 & 48 & 42.4 & 43.5 \\
\hline
\end{tabular}

\footnotetext{
${ }^{10}$ Numbers are taken from the World Development Indicator in 2012.

${ }^{11}$ For around 2008 refers always to last available value before 2010 if value for 2008 is not available.

${ }^{12}$ For comparison: in 2000 it was reported for the USA 40.8, for Germany 28.3, and for Switzerland 33.7

${ }^{13}$ Paraguay was pretty poor in the 80 s but with probably a low Gini of about 40 . If so, the mean was 51.6

${ }^{14}$ But even of 7.2 if Paraguay is counted with a Gini of 40.
} 
Table 2 provides the Gini indices of ASEAN for around 2008 and the 80s. We realize a lower inequality throughout ASEAN than for Latin America. The average was 42.1, going slightly down to 41.4. Even though the Gini changed for all countries over the last few decades, the mean is still about the same but has not increased albeit the opening of domestic markets. Admittedly, this result is again not weighted by population. What can be seen clearly is the strong decrease in the dispersion of the Gini between countries which went down from 6.37 to 4.68 during the same period. Therefore, similar to Latin America, we see that income distributions in this South-South RIA becoming more similar $^{15}$ without increasing the average inequality within country (i.e., the average Gini).

Table 2. Gini indices for ASEAN

\begin{tabular}{|c|c|c|c|c|c|c|c|c|c|}
\hline & Cambodia & Indonesia & Laos & Malaysia & PapuaNG & Philipp. & Singapore & Thailand & Vietnam \\
\hline Mid 80s & 41.9 & 36.8 & 36.7 & 46.2 & 50.9 & 44 & 42.5 & 42 & 37.6 \\
\hline Around 2008 & 38.2 & 40 & 30.4 & 48.6 & 50.9 & 41 & 43 & 45.2 & 35.7 \\
\hline
\end{tabular}

In Table 3, the Gini indices for the African countries are given. As we face three South-South RIAs, we have also summarized the descriptive statistics ${ }^{16}$ in Table 4. For all RIAs, we see one clear and unique tendency: they do not only converge towards similar Ginis shown by the dispersion, last line in Table 4, but at the same time have succeeded to reduce inequality inside their countries on average. Again, we are considering each country as a global player ${ }^{17}$, i.e., they do not account for different population sizes. Both tendencies are strongest for the WAEMU member states.

\footnotetext{
${ }^{15}$ We are so far neglecting the mean which is reflected in the GDP p.c. and considered in the context of sigma convergence in the next Sections.

${ }^{16}$ Missing values were replaced by the values '2008' (no data from former dates available). Now available numbers for 2011 say that Sierra Leone decreased inequality notably by about 5 points. So we suppose that the found tendencies were even more emphasized if calculations could be done with complete data.

${ }^{17}$ Alternatively, it could be interesting to see how the entire inequality, say the Gini of each RIA has developed. Note that this cannot be obtained by weighting the singular Ginis of each country by its population size. Instead, one could look at the income distributions of each country and aggregate them accordingly. This, however, requires the construction of these distributions over a long period.
} 
Table 3. Gini indices for West/Central Africa

\begin{tabular}{|c|c|c|c|c|c|c|c|c|c|c|}
\hline & Benin & BurkinaF & Cameroon & C.Verde & CentralA & Chad & CongoR & C.d'Ivore & Gabon & Gambia \\
\hline Mid 80s & -- & 50.7 & 46.8 & -- & 61.3 & - & -- & 41.2 & -- & 50.2 \\
\hline Around 2008 & 38.6 & 39.6 & 38.9 & 50.5 & 56.3 & 39.8 & 47.3 & 41.5 & 41.5 & 47.3 \\
\hline
\end{tabular}

\begin{tabular}{|c|c|c|c|c|c|c|c|c|c|c|}
\hline & Ghana & Guinea & GuineaB & Mali & Mauritania & Niger & Nigeria & Senegal & SierraLeone & Togo \\
\hline Mid 80s & 35.4 & 46.8 & 47.8 & 36.5 & 43.9 & 36.1 & 38.7 & 54.1 & -- & - \\
\hline Around 2008 & 42.8 & 39.4 & 35.5 & 39 & 38.9 & 34 & 42.9 & 39.2 & 42.5 & 34.4 \\
\hline
\end{tabular}

Table 4. Summary for Gini indices for West/Central Africa

\begin{tabular}{|l|c|c|c|c|c|c|}
\hline & \multicolumn{2}{|c|}{ CEMAC } & \multicolumn{2}{c|}{ WAEMU } & \multicolumn{2}{c|}{ ECOWAS } \\
\hline & $80 \mathrm{~s}$ & 2008 & $80 \mathrm{~s}$ & 2008 & $80 \mathrm{~s}$ & 2008 \\
\hline Means & 47.3 & 44.8 & 42.4 & 37.7 & 43.2 & 40.4 \\
\hline Dispersion & 7.56 & 6.47 & 6.98 & 2.55 & 6.28 & 4.31 \\
\hline
\end{tabular}

Next, we concentrate on the dispersion between the mean incomes of the members inside each RIA. This is done by studying the sigma paths of the different GDPs per capita.

\section{Looking at The Mean Income (Sigma-Convergence)}

In order to study the income dispersion between countries and to check for sigmaconvergence, it is recommendable to eliminate business cycle effects. This can be done by applying the filter of Hodrick and Prescott (1997) to separate the trend from the cyclical component. We consider $\ln y_{t}=g_{t}+c_{t}$ for $t=1$....T, where $y_{t}$ is GDP per capita, 
$c_{t}$ the cyclical component to be filtered out, and $g_{t}$ the growth component of interest. As only the $y_{t}$ are observed, the trend has to be calculated via a linear programming problem of the form

$$
\min _{\left\{g_{t}\right\}_{t=1}^{T}}^{\min } \sum_{t=1}^{T}\left(\ln y_{t}-g_{t}\right)^{2}+\lambda \sum_{t=2}^{T-1}\left[\left(g_{t+1}-g_{t}\right)-\left(g_{t}-g_{t-1}\right)\right]^{2}
$$

That is, the filter computes the stochastic trend of interest $\left\{g_{t}\right\}_{t=1}^{T}$ by minimizing the sum of squares of its second difference. The parameter, $\lambda$, penalizes the variability in the time series and is fixed in our context to be 100, following the arguments of Hodrick and Prescott. ${ }^{18}$ Generally, there is no perfect method to eliminate business cycle effects, because of the natural distortion in the data. In order to assess the impact of the smoothing parameter $\lambda$, we repeated the study with the three-year moving averages of all unfiltered GDP series to compute the sigma values of all RIAs and country sets under consideration. These studies lead to basically the same results.

Figure 11 compares the dispersion of income in Latin America. We see nonmonotonous trends of income dispersion for the set of the MERCOSUR and the ANDEAN states. According to the classical growth model, monotonically decreasing trends are expected. Both samples indicate some convergence since 1994. Even if we compare only the years 1985 and 2008, we find for ANDEAN and MERCOSUR (plus associates states), a lower sigma values for 2008, cf. also appendix 4. Together with the findings of Sperlich and Sperlich (2011), one can therefore conclude beta and sigma convergence in the MERCOSUR and ANDEAN. Poorer countries like Bolivia are growing faster (in percentage) than the richer countries causing beta convergence. However, in Figure 2 we saw that the gap between the poorest and the richest country of the ANDEAN states stayed nearly the same during that period but the income level increased for all. Also, if we compare the absolute values or the per capita income of the considered Latin American countries over time, we see that the log-income dispersion decreased, comparing 1985 with 2008 in Figure 2 albeit for the MERCOSUR founders the gap between poorest (Paraguay) and richest (Argentina) increased. In fact, different to Blyde (2005), we find a divergent sigma trend for the set of the four MERCOSUR

\footnotetext{
${ }^{18}$ This parameter should be approximately the ratio of the variance of the cyclical component divided by the variance of the second differences of the growth components. This gives a value of 1600 for $\lambda$ when assuming a $5 \%$ cyclical component and a $1 / 8$ of $1 \%$ change in the growth rate in a quarter. Therefore in STATA this is the default for $\lambda$ what refers to quarterly data. For our yearly data we tried 100 and 400 as we partly face emerging markets.
} 
founders.

On the other hand, Figure 11 shows that the MERCOSUR founders have had clearly lower income dispersion than the enlarged set having the associated members included. Summarizing, the (log) income dispersion in Latin America has decreased due to the relatively higher growth rates of poorer countries causing beta and sigma (log-income) convergence.

Figure 11. Sigma trends for Latin America based on HP filtered log-income

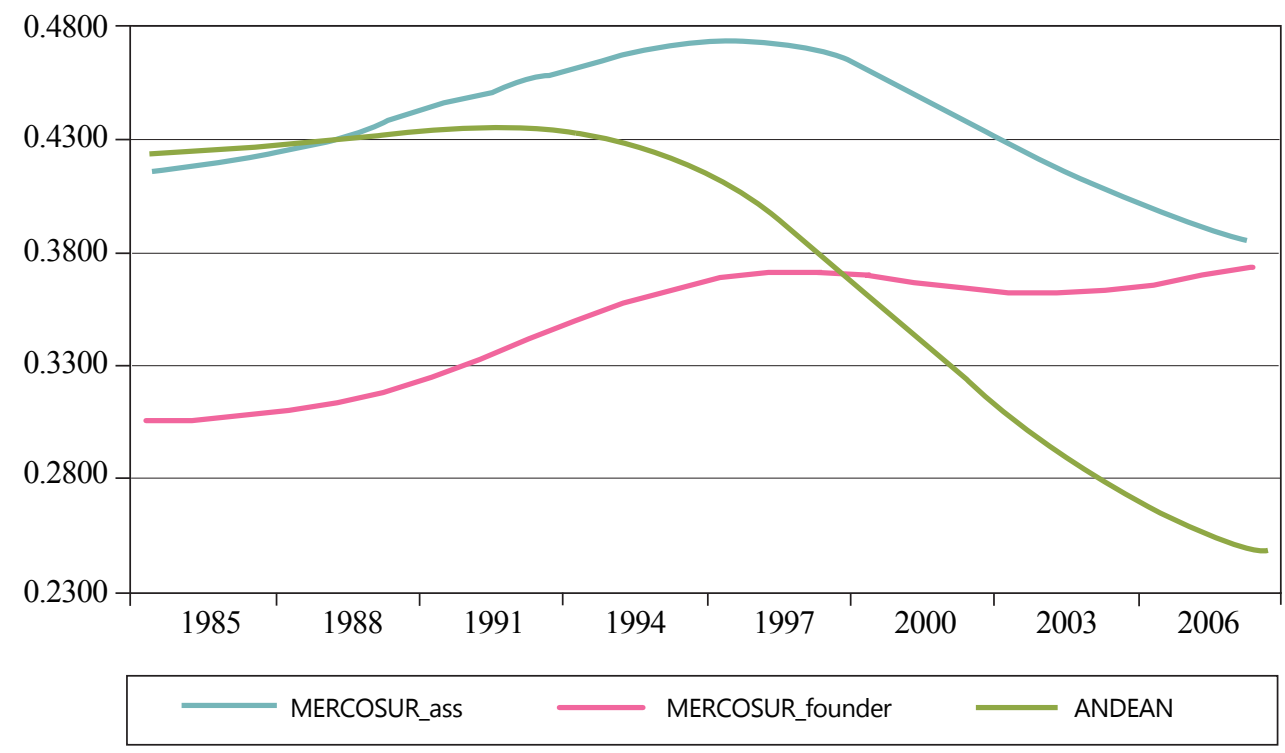

The empirical outcomes for ASEAN members can be seen in Figure 12 and Appendix 5. The income dispersion increased from 0.6211 in 1975 to 1.109 in 2008. The upward jump of the sigma at the beginning of the 80 s were due to the new members entries. In the 90s, these new member states were developing countries like Cambodia, Vietnam, and Laos. ${ }^{19}$ But even if only looking at the five founder states, we realize that the dispersion of per capita income rose from 0.6884 to 1.111 during the studied period.

These results are in accordance with those of Lim and McAleer (2004). They also considered the development of sigma without Singapore - today the financial centre of this area but one of the five founders of ASEAN. Without Singapore, the sigma of the ASEAN founders decreased until 1990 before it recovered back to its original state in

\footnotetext{
${ }^{19}$ Like Burma (Myanmar) which has not been included in the empirical analyses due to the lack of data.
} 
2003. Lim and McAleer's results differ in this point, because they studied a different period and did not eliminate the business cycles. Although we can observe that the poorest founder, Indonesia, grew faster than the others, implying beta convergence, the income gap between the states slowly widened. In other words, the growth path of the poorer countries did not increase sufficiently to cause sigma convergence so we do not find any sigma convergence with or without including Singapore or ignoring the new entries of poor countries. Fully accounting for these entries is hardly possible as the counterfactual exercise, which estimates the sigma-trend if no new members joined ASEAN, is empirically not possible, and even its prediction is only possible under strong (model) assumptions.

Figure 12. HP-filtered sigma trends in East Asia

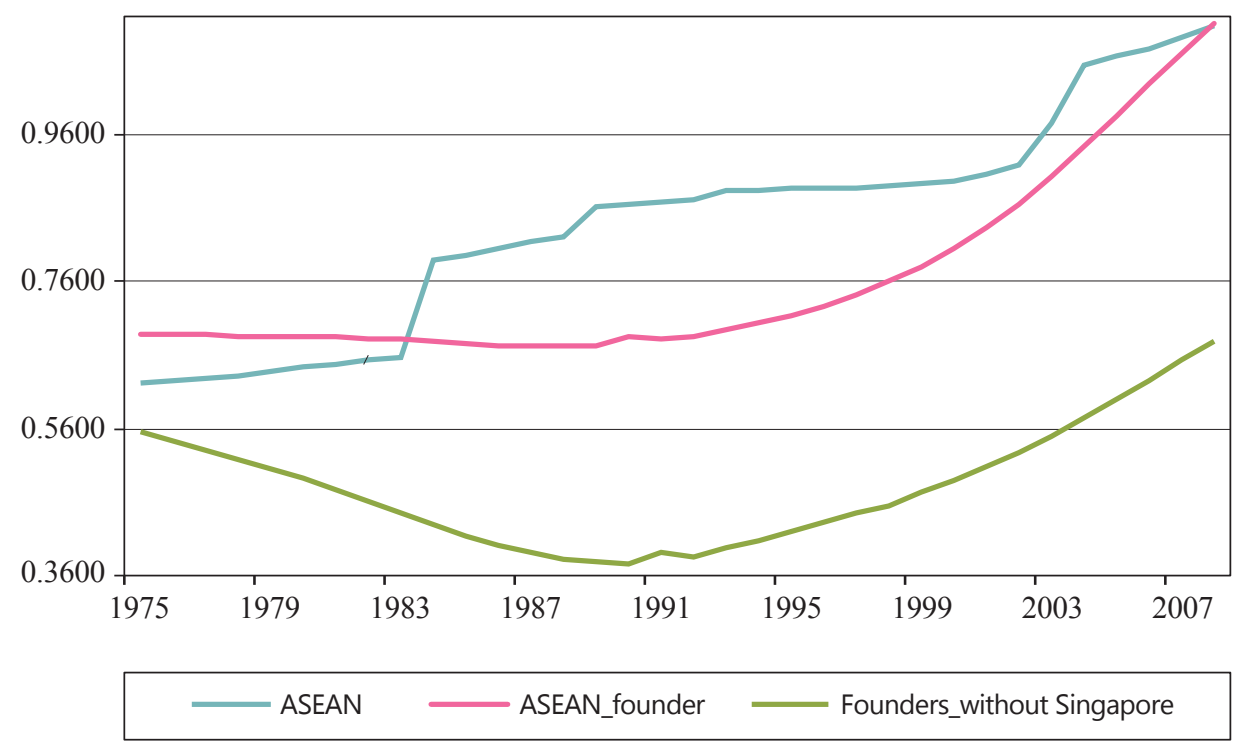

The empirical results for West and Central Africa are plotted in Figure 13 and also Appendix $6 .^{20}$ Clearly, CEMAC exhibits by far the highest income dispersion among the selected African South-South integration areas. For the WAEMU, we observe the lowest dispersion. The income dispersion of ECOWAS fell from 1975 1985 but jumped upwards immediately afterwards. This was simply due to the inclusion of Cape Verde

\footnotetext{
${ }^{20}$ Sigma convergence of different African RIAs was also studied by Hammouda, Karingi, Njuguna, and Jallab (2007) but for different time periods and data manipulation (treating with business cycles etc.).
} 
in 1986, currently the country with the highest per capita income in ECOWAS. The dispersion of income continued to increase mainly because of the positive development of Cape Verde, and because of the negative economic development of Sierra Leone, now the poorest country in ECOWAS.

Figure 13. HP-filtered sigma trends in West- and Central Africa

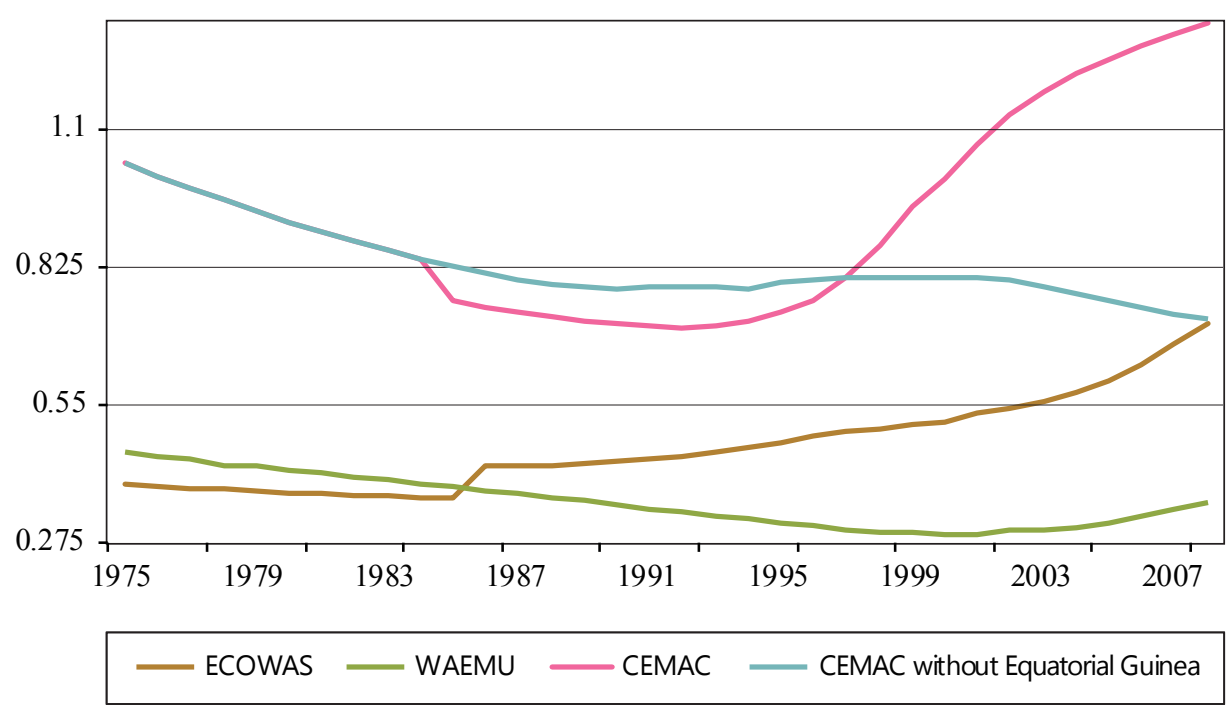

The WAEMU shows sigma convergence until 2001, and a slight divergence afterward. Taking this together with the findings of Sperlich and Sperlich (2011), we conclude that here poorer countries indeed grew faster than richer ones (beta convergence) in such a way that the log-income gap among the member states decreased notably. As it can be seen in Figure 8, the distance of the log per capita income between the richest and the poorest partners became smaller. However, we can not observe a homogenous development. Nations like Senegal and Benin have caught up to the initial regional economic leader Cote d'Ivoire. Some other countries like Niger have stagnated since the mid 80s, and that of Guinea-Bissau since the mid 90s.

For CEMAC, we first find a decreasing sigma until 1993. But then there is a change in the trend and the income dispersion rises. Figure 6 exhibits the reason: the economic boom of Equatorial Guinea, driven by oil, compared to the relative low growth rates in the other five member states, resulting in a strongly increasing dispersion. For a better comparison, we also calculated the sigma trend without Equatorial Guinea as shown 
in Figure 13. Then one finds clear and steady sigma convergence, demonstrating that the sigma increase inside CEMAC was indeed only due to the oil fields in Equatorial Guinea.

\section{Sigma-convergence to Beta-convergence}

Sperlich and Sperlich (2011) found unconditional and conditional beta convergence in all South-South RIAs considered in this paper. Moreover, the analysis showed that the membership has had a positive impact on both beta convergence and growth for all RIAs considered here. In order to compare these results with sigma development, we have used the same data sets. As it is known from the literature, in a linear separable Solow growth model, beta convergence can lead to either a monotone decrease or increase of the standard deviation when neglecting the business cycles. In other words, sigma divergence is not in contradiction to beta convergence, and thus, sigma divergence would not be in conflict with our findings. Several concerns exist regarding the sigma convergence criterion, heterogeneity and most of the natural dynamics are ignored. Country or group specific shocks are thus neglected; sigma trends simply capture the evolution of cross-section income distribution towards an invariant measure (Durlauf, Johnson, and Temple 2005). Or, as Quah (1993) mentioned, sigma convergence means that each country eventually becomes as rich as all the others - the cross section dispersion diminishes over time. As a consequence, no information is obtained about distribution dynamics within the considered group(s), such as mobility, stratification, and polarization (Quah 1996, 1997, or Durlauf, Johnson, and Temple 2005). Moreover, it is well-known that a main effect of regional integration is its impact on infrastructure and institutions (Sperlich and Sperlich 2012), which in turn have an important impact on development and growth.

Let us revise the relation between beta and sigma convergence starting from the classical unconditional Solow model, with $\ln y_{i, t}$ denoting the logarithm of per capita income of country $i$ and time $t$, a constant $a$, a parameter $\gamma$ which is proportional to the sum of labor force growth, technological progress, and depreciation rate, and finally a mean zero disturbance term $\varepsilon_{i, t}$ to capture heterogeneity over time and between countries: 


$$
\ln y_{i, t}-\ln y_{i, t-1}=a-\left(1-e^{-\gamma}\right) \ln \left(y_{i, t-1}\right)+\varepsilon_{i, t}, \text { where } i=1,2, \ldots, N, t=1,2, \ldots, T
$$

For each period then, $y_{i, t-1}$ is the initial per capita income. Replacing $\left(1-e^{-\gamma}\right)$ by $-\beta$ one has

$$
\ln y_{i, t}=a+(1+\beta) \ln y_{i, t-1}+\varepsilon_{i, t}
$$

For the ease of calculus, the shocks $\varepsilon_{i, t}$ with $E\left(\varepsilon_{i, t}\right)=0$ are typically assumed to be independently distributed over time and space and also homoscedastic, that is they have the same variance $\sigma_{\varepsilon}{ }^{2}$ for each country $i$ and time $t$. Clearly, this is a strong and unrealistic simplification with some important implications. The cross-sectional dispersion of $\log$ income is $\sigma_{t}^{2}=\operatorname{Var}\left(\ln y_{t}\right)$, can be estimated via

$$
\hat{\sigma}_{t}^{2}=(1 / N) \sum_{i=1}^{N}\left[\ln \left(y_{i, t}\right)-\overline{\ln \left(y_{t}\right)}\right]^{2}
$$

where $\overline{\ln \left(y_{t}\right)}$ is the average of $\ln \left(\mathrm{y}_{\mathrm{i}, \mathrm{t}}\right)$ in year $t$. The variance decomposition of (1), gives

$$
\sigma_{t}^{2}=\sigma_{t-1}^{2}(1+\beta)^{2}+\sigma_{\varepsilon}^{2}
$$

If we do not assume that income dispersion tends to zero but consider a steady state of the Solow model instead, in which $\sigma_{t^{-}}=\sigma_{t}=\sigma^{*}$, then

$$
\left(\sigma^{*}\right)^{2}=(1+\beta)^{2}\left(\sigma^{*}\right)^{2}+\sigma_{\varepsilon}^{2} \Leftrightarrow\left[1-(1+\beta)^{2}\right]\left(\sigma^{*}\right)^{2}=\sigma_{\varepsilon}^{2}
$$

which is only defined for $-2 \leq \beta \leq 0$. Thus, the steady state variance depends on the shock dispersion and on $\beta$ with $\sigma_{\varepsilon}=\sigma^{*}$ for $\beta=-1$ and $\sigma_{\varepsilon} \leq \sigma^{*}$ otherwise. Plugging-in gives

$$
\sigma_{t}^{2}=\sigma_{t-1}^{2}(1+\beta)^{2}+\left(\sigma^{*}\right)^{2}-(1+\beta)^{2}\left(\sigma^{*}\right)^{2} \Leftrightarrow \sigma_{t}^{2}-\left(\sigma^{*}\right)^{2}=(1+\beta)^{2}\left[\sigma_{t-1}^{2}-\left(\sigma^{*}\right)^{2}\right]
$$

If $0>\beta>-2$ ( $\beta$-convergence), then one has convergence of the log income dispersion toward the steady state $\sigma^{*}$ which is not necessarily smaller than the present sigma. So beta convergence may require sigma divergence. For other cases, the Equation (4) 
are not even defined. Moreover, Equation (3) shows that as the shock dispersion $\sigma_{\varepsilon}$ is never negative, sigma convergence requires $\beta$-convergence. For the unconditional Solow model this means that RIAs with sigma-divergence despite beta-convergence, the income dispersion is above the steady state level. If income convergence is a target of the RIA, then it is natural to assume that the steady state sigma is rather small and definitely smaller than the present dispersion. Both beta and sigma convergence would then be an objective.

Due to our linear model, the sigma evolution to the steady state is supposed to run monotonically, especially when the series have been cleaned from business cycles. In general, however, the sigma should rise or fall depending upon conditional steady states, thinking if the conditional Solow model that includes human capital, investment or simply because of heteroscedasticity. In either case, $\sigma_{\varepsilon}$ in Equations (3) and (4) has to be replaced by a positive function of conditioning variables, say $x$. In case of correlation between these conditioning variables and the past income, Equations (3) and (4) have further to be enlarged by a term containing covariances which might be negative. But notice that already heteroscedasticity of $\sigma_{t}(x)$ and $\sigma_{t-1}(x)$ will allow for an oscillating adjustment of sigmas to their steady state, no matter whether that is a conditional one or not.

If we assume that all member states of one RIA face the same steady state, that it is sufficient to consider the unconditional growth model, then the upwards shape of sigma curves can be explained by higher steady state dispersion, and oscillating sigmas by heteroscedasticity. If we additionally allow for conditional steady states, then income dispersion can simply increase due to divergent $x$ inside a RIA. Not surprisingly, for income convergence of a RIA, it is therefore essential to homogenize the conditions for growth. But this is exactly what we claim South-South RIAs are good for, recall our discussion in the first section and the official targets of the considered RIAs.

\section{Conclusion}

Reviewing the theories about regional integration and growth, one finds ambiguous predictions with pro and contra arguments for the so-called South-South areas. Somewhat, in contrast to the exclusively theory based criticism, Sperlich and Sperlich (2011) found empirical evidence for enhanced growth and convergence for the members 
of these agreements. An argument that may explain the apparent contradiction is that the theoretical studies often abstract from conditions other than trade, technological transfer or very specific economic factors. As we have seen in Section II, obstacles for economic growth and sustainable development in the Southern hemisphere are of political nature like stability, infrastructure, and regional coordination. Those are often promoted by South-South agreements, and can therefore have a positive impact on growth and development (Glaeser, La Porta, Lopez-De-Silanes, and Shleifer 2004).

Based on empirical evidence, this paper answers quite important question politically, on the convergence of income distributions in South-South RIAs. The former papers did not say much about the dispersion of income, neither within nor between countries; the classical growth model predicts only that if there is beta convergence, then the sigma falls or rises what refers only to the convergence of means between countries. As such, a mean income (GDP per capita) is a quite limited parameter, our study comprises also a parameter of income dispersion, namely the Gini index. We find that inside most RIAs, the member states tend to converge in the sense that they become more similar concerning their income distributions when looking at inequality and mean. Moreover, it turned out that all RIAs succeeded in both reducing the inequality in average and convergence towards similar income structures. This contradicts the hypothesis that this kind of RIAs may promote growth but also inequality: this is neither the case within nor between member states. Maybe surprisingly, the less evident is the sigma-convergence which is not confirmed when just taking the pure data. However with figures in Section II, we can typically detect a simple explanation such as oil-fields in a member state or new entries of poor countries.

Policy implications are as follows;

- The revision of the individual GDP (per capita) growth paths reveals that the negative shocks are mostly provoked by political instability, and that this is probably the main stumbling block for the development of the considered countries. The second one, again revealed from the careful study of the individual growth paths, is the strong dependency on the world market for certain good. In both issues South-South-RIAs can significantly help to improve economies. So integration agendas should also concentrate on "behind-the-border-issues" like infrastructure and institutional projects, not focusing only on trade facilitations. Concerning the latter, it is probably rather the bargaining power than the free-trade per se that makes South-South-RIAs attractive for their members. 
- Together with related work, e.g. Sperlich and Sperlich (2011), Sperlich and Sperlich (2012), one can conclude from this study that, contrary to many theoretical studies, there is empirical evidence that the member countries do economically benefit from South-South-RIAs.

- Inequality between members is decreasing in almost all RIAs. But it remains important to build up efficient compensation mechanisms.

- On the other hand, this implicates also that some members benefit much more than others, i.e. the benefit is heterogeneous what has already led to dissatisfaction in countries that believe to benefit less. This means that compensation mechanisms, have to be applied carefully.

- However, inequality within countries in South-South RIAs is still very high (e.g. in Brazil, Central African Rep. and Colombia etc.) - here political measures are necessary and urgent as increasing inequality bears the danger of political instability.

- Rationalization of overlapping RIAs in Sub-Sahara-Africa and Asia needs a forward-looking integration agenda. We cannot say whether several small or a few large RIAs are better for countries but we see that many overlapping RIAs are rather hindering than fostering.

- More detailed studies are necessary about (a) potential effects of RIArationalizations, especially in Africa, (b) the heterogeneity of RIA-membership effects over the different states in order to deal with the concerns of countries, believing they have been disadvantaged.

Received 23 April 2012, Revised 24 March 2014, Accepted 15 October 2014

\section{References}

Baldwin, Richard E., Philippe Martin and Gianmarco I.P. Ottaviano. "Global Income Divergence, Trade, and Industrialization: The Geography of Growth Take-Offs." Journal of Economic Growth 6 (2001): 5-37.

Barro, Robert J. and Xavier Sala-i-Martin. "Convergence." The Journal of Political Economy 100 (1992): 223-251. 
Ben-David, Dan. "Equalizing exchange: Trade Liberalization and Income Convergence." The Quarterly Journal of Economics 108 (1993): 653-679.

Blyde, Juan S. "Convergence in Mercosur." Journal of Economic Integration 21 (2006):784-815.

Bulmer-Thomas, Victor. "The Economic History of Latin America since Independence $2^{\text {nd }}$ edition." Cambridge: Cambridge University Press, 2003.

Durlauf, Steven N., Paul A. Johnson and Jonathan Temple. "Growth Econometrics." Handbook of Economic Growth 1 (2005): 555-677.

Fugazza, Macro and Frederic Robert-Nicoud. "Can South-South Trade Liberalization Stimulate North-South Trade?" Journal of Economic Integration 21 (2006): 234-253.

Galor, Oded. "Convergence? Inferences from Theoretical Models." The Economic Journal 106 (1996): 1056-1069.

Glaeser, Edward L., Rafael La Porta, Florencio Lopez-De-Silanes, and Andrei Shleifer. “Do Institutions Cause Growth?” Journal of Economic Growth 9 (2004): 271-303.

Goodfriend, Marvin and John McDermott. "Industrial Development and the Convergence Question.” American Economic Review 88 (1998): 1277-1289.

Goretti, Manuela and Hans Weisfeld. "Trade in the WAEMU: Development and Trade Opportunities." IMF WP 68 (2008).

Hammouda, Hakim B., Stephen N. Karingi, Angelica E. Njuguna and Mustapha S. Jallab. "Why Doesn't Regional Integration Improve Income Convergence in Africa?" African Development Review 21 (2009): 291-330.

Hill, Hal. "ASEAN Economic Development: An Analytical Survey- The State of the Field." Journal of Asian Studies 53 (1994): 832-866.

Hodrick, Robert J. and Edward C. Prescott. "Post-war U.S. Business Cycles: An Empirical Investigation.” Journal of Money, Credit and Banking 29 (1997): 1-16.

Krugman, Paul. "Geography and Trade.” Cambridge: MIT Press, 1991.

Lim, Lee K. and Michael McAleer. "Catching up and Convergence in ASEAN: A Comparative Analysis.” Applied Economics 36 (2004): 137-153.

Sanguinetti, Pablo, Iulia Siedschlag and Christian Martincus. "The Impact of South- 
South Preferential Trade Agreements on Industrial Development: An Empirical Test." Journal of Economic Integration 25 (2010): 69-104.

Michelis, Leo and Simon Neaime. "Convergence in Mercosur." Journal of Economic Integration, 19 (2004): 470-498.

Oyebade, Adebayo and Abiodun Alao. "Africa after the Cold War: The Changing Perspectives in Security." Trenton: Africa World Press, Inc, 1998.

Panizza, Ugo. "Income Inequality and Economic Growth: Evidence from American Data." Journal of Economic Growth 7 (2002): 25-41.

Quah, Danny T. "Galton's Fallacy and Tests of the Convergence Hypothesis." The Scandinavian Journal of Economics 95 (1993): 427-443.

Quah, Danny T. "Twin Peaks: Growth and Convergence in Models of Distribution Dynamics." The Economic Journal 106 (1996): 1045-1055.

Quah, Danny T. "Empirics of Growth and Distribution: Stratification, Polarization and Convergence Clubs.” Journal of Economic Growth 106 (1997): 1045-1055.

Ravallion, Martin. "Growth, Inequality and Poverty: Looking beyond Averages." World Development 29 (2001): 1803-1815.

Rey, Sergio J. and Mark V. Janikas. "Regional Convergence, Inequality and Space." Journal of Economic Geography 5 (2005): 155-176.

Sala-i-Martin, Xavier. "Regional Cohesion: Evidence and Theories of Regional Growth and Cconvergence.” European Economic Review 40 (1996): 1325-1352.

Sperlich, Stefan and Yvonne Sperlich. "Growth and Convergence in South-South Integration Areas: The Empirical Evidence.” WP at University Geneva (2011).

Sperlich, Yvonne and Stefan Sperlich. "Practical Tools for Monitoring Convergence and Development Focusing on Integration Areas." Journal of Comparative Policy Analysis 14 (2012): 72-103.

Te Velde, Dirk W. "Regional Integration, Growth and Convergence." Journal of Economic Integration 26 (2011): 1-28.

Thorp, Rosemary. "Progress, Poverty and Exclusion: An Economic History of Latin America in the 20th century." Washington: Inter-American Development Bank, 1998. 


\section{Appendices}

\section{Appendix 1. ANDEAN and MERCOSUR}

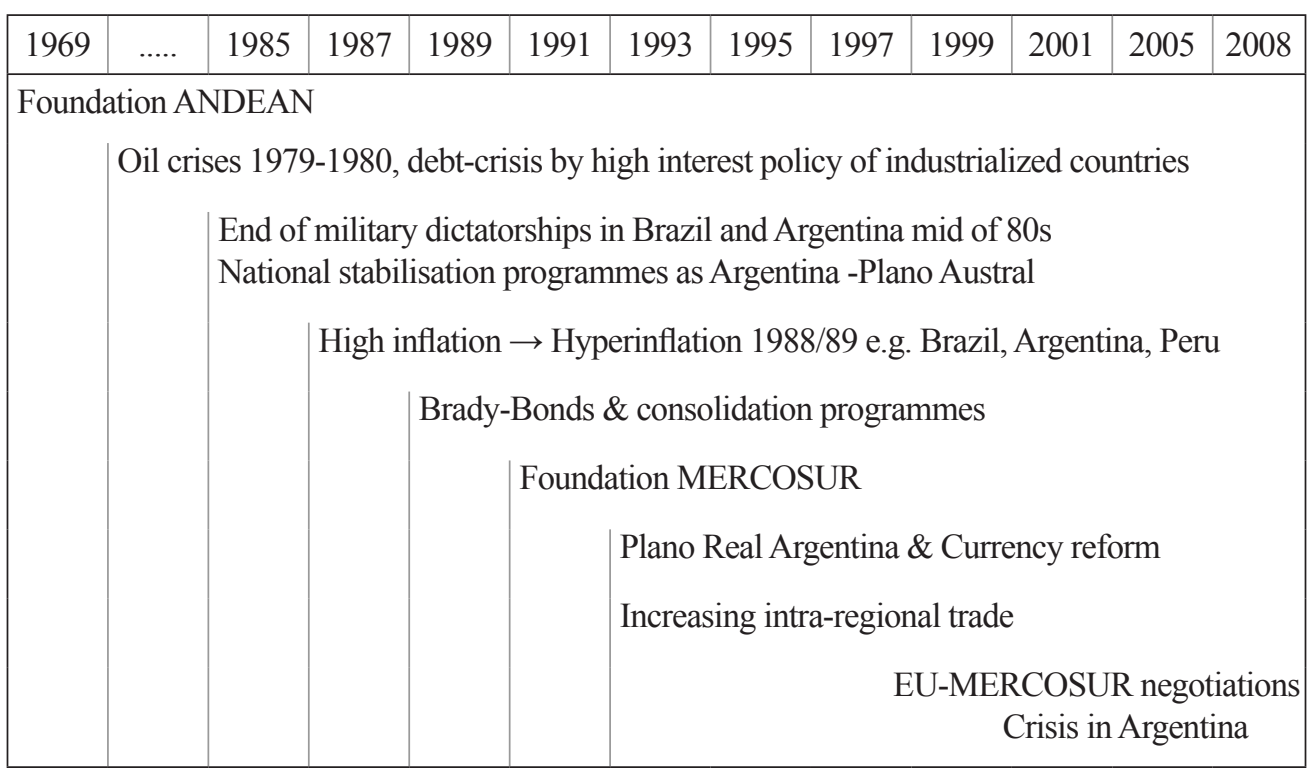

\section{Appendix 2. ASEAN}

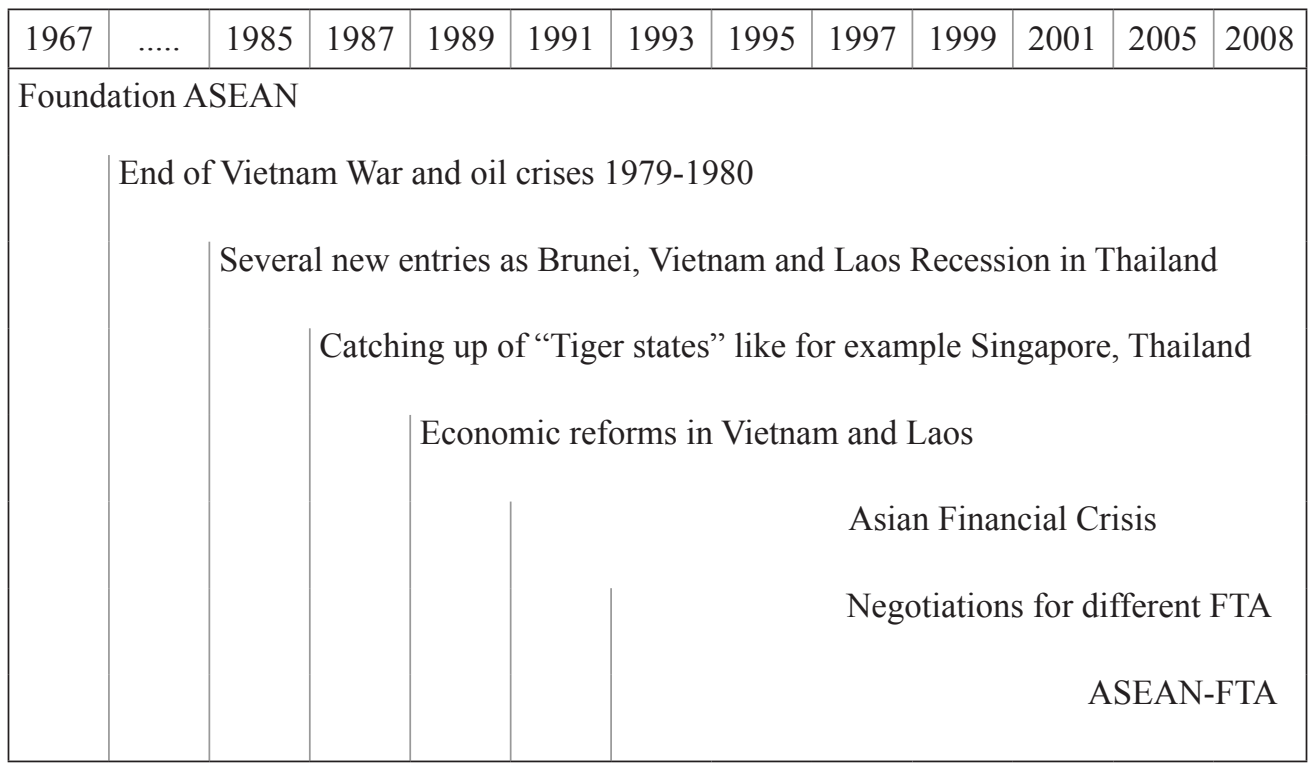




\section{Appendix 3. ECOWAS, CEMAC, WAEMU}

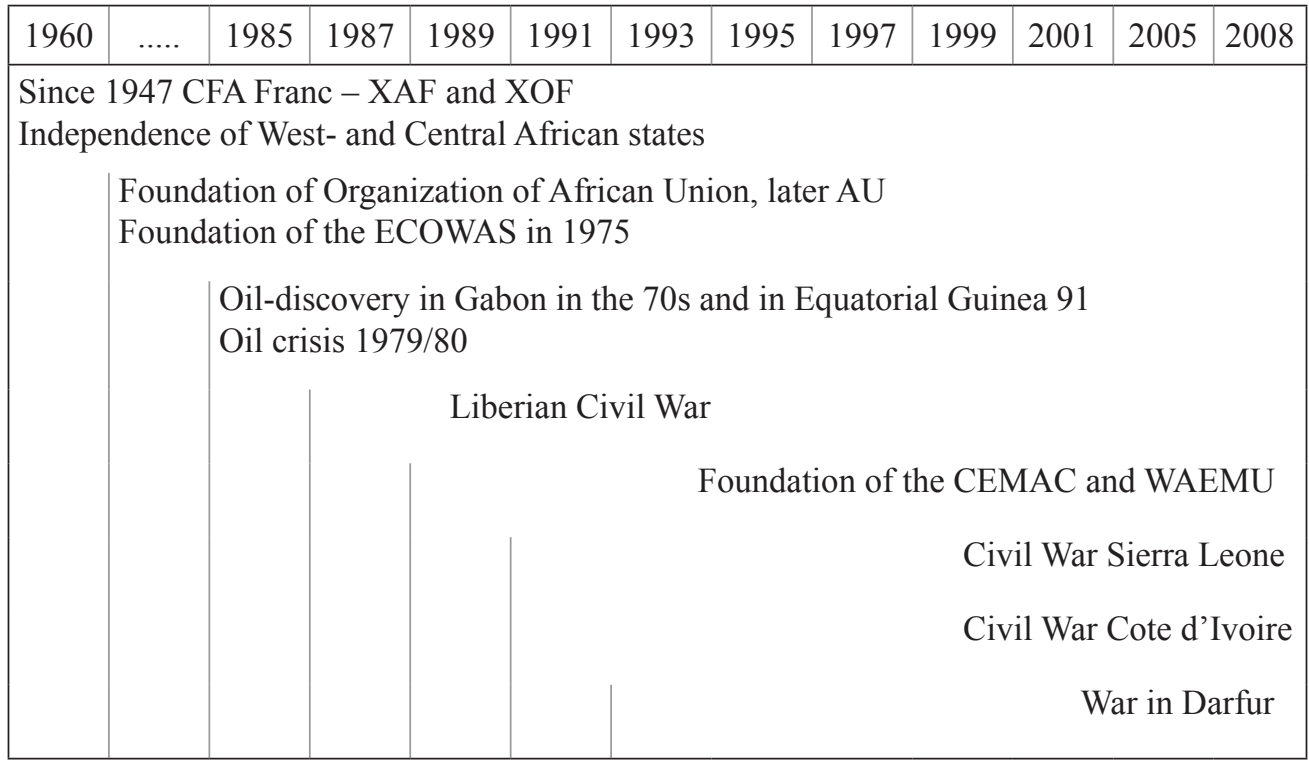


Appendix 4. Log-income dispersion (HP-filtered data) in MERCOSUR \& ANDEAN

\begin{tabular}{|c|c|c|c|}
\hline & All & Founders & ANDEAN \\
\hline $\mathbf{1 9 8 5}$ & 0.4158 & 0.3074 & 0.4244 \\
\hline $\mathbf{1 9 9 0}$ & 0.4398 & 0.3194 & 0.4325 \\
\hline $\mathbf{1 9 9 5}$ & 0.4721 & 0.3584 & 0.4244 \\
\hline $\mathbf{2 0 0 0}$ & 0.4585 & 0.3709 & 0.3600 \\
\hline $\mathbf{2 0 0 5}$ & 0.4042 & 0.3643 & 0.2747 \\
\hline $\mathbf{2 0 0 8}$ & 0.3847 & 0.3750 & 0.2496 \\
\hline
\end{tabular}

Appendix 5. Log-income dispersion (HP-filtered data) for ASEAN

\begin{tabular}{|c|c|c|c|}
\hline & ASEAN & Founders & Founders without Singapore \\
\hline $\mathbf{1 9 7 5}$ & 0.6211 & 0.6884 & 0.5565 \\
\hline $\mathbf{1 9 8 0}$ & 0.6431 & 0.6853 & 0.4912 \\
\hline $\mathbf{1 9 8 5}$ & 0.7971 & 0.6755 & 0.4146 \\
\hline $\mathbf{1 9 9 0}$ & 0.8652 & 0.6763 & 0.3763 \\
\hline $\mathbf{1 9 9 5}$ & 0.8868 & 0.7147 & 0.4194 \\
\hline $\mathbf{2 0 0 0}$ & 0.8982 & 0.8042 & 0.4888 \\
\hline $\mathbf{2 0 0 5}$ & 1.0660 & 0.9866 & 0.6005 \\
\hline $\mathbf{2 0 0 8}$ & 1.1091 & 1.1115 & 0.6776 \\
\hline
\end{tabular}


Appendix 6. Log-income dispersion (HP-filtered data) for West- and Central Africa

\begin{tabular}{|c|c|c|c|c|}
\hline & CEMAC & IEGuinea & WAEMU & ECOWAS \\
\hline $\mathbf{1 9 7 5}$ & \multicolumn{2}{|c|}{1.0323} & 0.4525 & 0.3881 \\
\hline $\mathbf{1 9 8 0}$ & \multicolumn{2}{|c|}{0.9143} & 0.4174 & 0.3733 \\
\hline $\mathbf{1 9 8 5}$ & \multicolumn{2}{|c|}{0.7586} & 0.3837 & 0.3601 \\
\hline $\mathbf{1 9 9 0}$ & \multicolumn{2}{|c|}{0.7077} & 0.3488 & 0.4351 \\
\hline $\mathbf{1 9 9 5}$ & \multicolumn{2}{|c|}{0.7335} & 0.3124 & 0.4742 \\
\hline $\mathbf{2 0 0 0}$ & 1.0021 & 0.2895 & 0.2895 & 0.5144 \\
\hline $\mathbf{2 0 0 5}$ & 1.2397 & 0.3127 & 0.3127 & 0.5967 \\
\hline $\mathbf{2 0 0 8}$ & 1.3140 & 0.3523 & 0.3523 & 0.7126 \\
\hline
\end{tabular}

(Note) $\backslash$ EGuinea indicates that the values after 1995 were calculated without Equatorial Guinea, i.e., when its oil boom started. 